\title{
Study of Work Ability Index (WAI) and Its Association with Demographic Characteristics Among Firefighters
}

\section{Ramin Rahmani $^{1}$ (D), Raheleh Hashemi Habybabady ${ }^{*}$ (D), Mohammad Hossein Mahmoudi ${ }^{3}$, Haniyeh Yousefi $^{4}$, Siavash Shahnavazi ${ }^{5}$}

1. MSc Student, Departmen of Occupational Hygiene Engineering, Student Research Committee, School of Public Health, Hamadan University of Medical Sciences, Hamadan, Iran

2. Assistant Professor of Occupational Hygiene Engineering, Health Promotion Research Center, Health School, Zahedan University of Medical Sciences, Zahedan, Iran

3. MSc Student, Department of Occupational Hygiene Engineering, Faculty of Health, Mazandaran University of Medical Sciences, Mazandaran, Iran

4. MSc Student of Ergonomics, Student Research Committee, School of Public Health, Hamadan University of Medical Sciences, Hamadan, Iran

5. BSc in Occupational Hygiene Engineering, Health School, Zahedan University of Medical Sciences, Zahedan, Iran

Article Info

Received: 2021/01/03;

Accepted: 2021/05/06;

ePublished: 2021/05/18

10.30699/jergon.9.1.63

Use your device to scan and read the article online

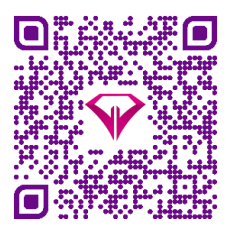

Corresponding Author Raheleh Hashemi Habybabady

Assistant Professor of

Occupational Hygiene

Engineering, Health Promotion

Research Center, Health School,

Zahedan University of Medical

Sciences, Zahedan, Iran

Email:

habybabady 568@yahoo.com

\section{ABSTRACT}

Background and Objectives: Assessing the workability of employees is very important, and firefighting is one of the critical jobs. Therefore, the aim of this study was to evaluate the work ability index (WAI), and identify some effective factors among firefighters.

Methods: This cross-sectional study was carried out with participation of 101 firefighters in Zahedan, Iran in 2018. Subjects were included in the study by census method. Data were collected using a two-part questionnaire (demographic information and WAI items), and data analysis was performed using SPSS 24.

Results: The mean of age and work experience of the subjects were $34.18 \pm 6.70$ and $8.47 \pm 6.79$ years, respectively. Only 18 individuals $(17.8 \%)$ were single, and most of them exercised at least once a week. The mean score of WAI was $44.33 \pm 3.56$ and most of the subjects were in the excellent range. With increasing age and work experience, WAI decreased, and there was also a significant relationship between marital status and weekly exercise with WAI.

Conclusion: In general, the condition of the firefighters was favorable in terms of workability. However, due to the relationship between personal characteristics and WAI, it is necessary to adjust the duties of older people with more work experience.

Keywords: Work Ability Index, WAI, Firefighters

\section{How to Cite This Article:}

Rahmani R, Hashemi Habybabady R, Mahmoudi M H, Yousefi H, Shahnavazi S. Study of Work Ability Index (WAI) and its association with demographic characteristics among Firefighters. Iran J Ergon. 2021; 9 (1) :63-74 


\section{Extended Abstract}

\section{Introduction}

Assessing the workability of employees is very important, and firefighting is one of the critical jobs. Therefore, the aim of this study was to evaluate the work ability index (WAI), and identify some effective factors among firefighters.

\section{Methods}

This cross-sectional study was carried out with participation of 101 firefighters in Zahedan, Iran in 2018. Subjects were included in the study by census method. Data were collected using a twopart questionnaire (demographic information and WAI items), and data analysis was performed using SPSS 24 (SPSS Inc., Chicago, IL., USA).

\section{Results}

The mean of age and work experience of the subjects were $34.18 \pm 6.70$ and $8.47 \pm 6.79$ years, respectively. Only 18 individuals (17.8\%) were single, and most of them exercised at least once a week. The mean score of WAI was $44.33 \pm 3.56$ and most of the subjects were in the excellent range. With increasing age and work experience, WAI decreased, and there was also a significant relationship between marital status and weekly exercise with WAI.

\section{Discussion}

The aim of this study was to study the work ability index and the factors affecting it in firefighters. In general, the results of this study showed that the average score of the work ability index among firefighters was 44.33 and this index was between 33 and 49. The value of work ability index in firefighters of Saremi et al.'s study was 38.85 , which was lower than the value obtained in our study [27]. Given that the mean age and work experience of firefighters in the two studies were similar, the difference in the value obtained can be attributed to the difference in other conditions. It is obvious that Zahedan firefighters have significant differences in lifestyle and working conditions compared to Tehran firefighters. Also, according to the results of a study published by Hatami and Afshari [25], the average work ability index was 34.65 , which was lower than the value in our study. Given that the selected firefighters in the Hatami and Afshari studies were operating in one of the petrochemical industries, they may have been influenced by some influential variables such as job stress or different weather conditions from the population studied in our study. In addition, as noted in the study by Saremi et al., mental workload can also affect work ability [27]. The results of a study conducted by Kiss et al. on older firefighters (mean age 51.5 years) [26] showed that the average work ability index was 40.6, which shows that older firefighters are less able to work compared to our study.

Based on the working ability index classes, it was found that most of the firefighters in the present study had excellent ability to do the job, and in general, the average was higher than most studies conducted on other occupational groups (other than firefighters). For example, Habibi et al. reported the Nursing Ability Index obtained in their study to be around 38, which was lower than in our study [32]. In addition, the results of the study by Akbari et al. showed that the index of ability to work in the employees of a cement factory was about 41 , which was also less than the value in our study [18]. One of the main reasons for the good working condition of most of the firefighters studied can be related to interviews and early employment tests. Due to the high sensitivity of the firefighting job, it is necessary for people with maximum ability to be selected for this job in order to achieve the maximum compatibility between humans and work [24].

According to the results of this study, there was an inverse linear relationship between age and ability to work in fire stations. In other words, older people were less able to work, and this result is consistent with previous studies in this field [25-27, 32]; while the findings of Akbari et al. were inconsistent with our study. They concluded that there is a positive correlation between age and work ability index [18]. The study of Kavousian et al. Also showed that with age increasing, the ability to work of individuals 
decreased, which is consistent with the results of our study [19]. Also, in the study of Bugajska et al., a negative correlation was observed between age and study subjects (both men and women) [33]. It is noteworthy that the relationship between age and the ability to work index in a 4-year study was similarly reported that increasing age is associated with a decrease in the ability to work [34].

The results of the present study also showed that there is a significant negative correlation between work ability index and work experience. In this regard, the research of Akbari et al. showed that the correlation between work experience and the ability to work in the employees of the cement plant was positive, which is not consistent with our results [18]. However, the results of Habibi et al.'s study on employees showed that people with high work experience had a lower ability to work, which was in line with the results of our study [32].

Another finding of this study was about comparing the ability to work in single and married people. Based on this, it was found that single people are more capable of doing work. A study by Saremi et al. also showed that marriage has a negative effect on the ability to work [27]. A study by Habibi et al. found that single people were more able to do work than married people [32] and that this could be due to stressors. Previous studies have shown that job stress levels in married women are higher than single, and on the other hand, it has been found that there is a negative correlation between stress and the ability to work [21].

The present study showed that regular exercise during the week is associated with increased ability to do work. Kavousian et al. concluded that the greatest ability to do work was related to a group of people who exercised on a daily basis [19]. Therefore, it is appropriate for managers of industries and organizations to design regular exercise programs and encourage employees to exercise in order to achieve higher levels of productivity of their employees.

\section{Conclusion}

In general, the condition of the firefighters was favorable in terms of workability. However, due to the relationship between personal characteristics and WAI, it is necessary to adjust the duties of older people with more work experience.

\section{Acknowledgement}

The authors of this article thank Mr. Babak Fazli, an honorable member of the faculty of the Occupational Health Department of Zahedan School of Health, for their valuable guidance. We also appreciate the good cooperation of the firefighters of Zahedan, especially Mr. Hamid Shaqoozeh, the Deputy Chief of Operations.

\section{Conflict of Interest}

The authors declared no conflict of interest. 


\section{مقالة يزووهشى}

\section{مطالعةُ شاخص توانايى كار (WAI) و ارتباط آن با ويثَى هاى فردى در آتشنشانها}

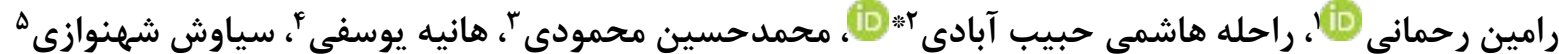

ا . ـ دانشجوى كارشناسى ارشد مهندسى بهداشت حرفهاى، كميتهٔ تحقيقات دانشجويى، دانشكده بهداشت، دانشگاه علوم يزشكى همدان، همدان، ايران

Y. استاديار مهندسى بهداشت حرفهاى، مركز تحقيقات ارتقاء سلامت، دانشكدة بهداشت، دانشكاه علوم يزشكى زاهدان، زاهدان، ايران

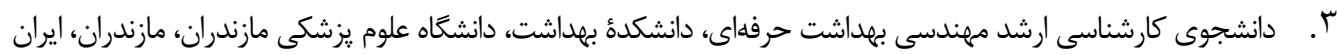

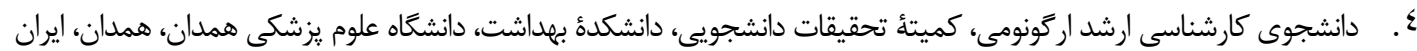

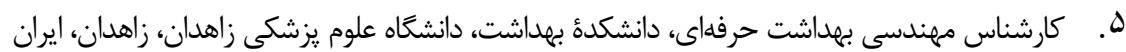

\begin{tabular}{|c|c|}
\hline 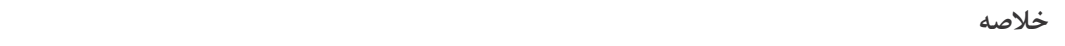 & 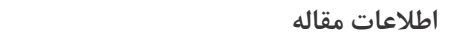 \\
\hline زمينه و هدف: ارزيابى توانايى جسمانى كاركنان براى انجام كار، حايز اهميت بوده و آتشنشانى يكى & 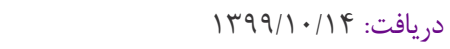 \\
\hline از شغلهاى حياتى است؛ لذا مطالعهُ حاضر با هدف ارزيابى شاخص توانايى كار و شناسايى برخى از & 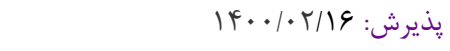 \\
\hline \multirow{5}{*}{ 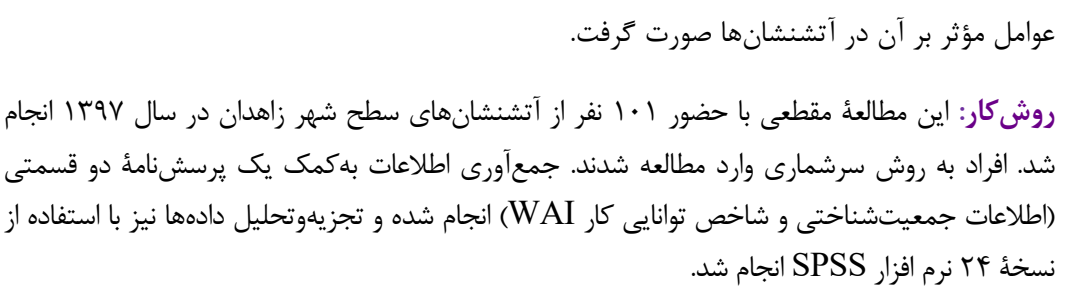 } & 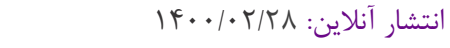 \\
\hline & نويسندهُ مسئول: \\
\hline & راحله هاشمى حبيب آبادى \\
\hline & استاديار مهندسى بهداشت حرفهاى، مركز \\
\hline & تحقيقات ارتقاء سلامت، دانشكدة بهداشت، \\
\hline \multirow{4}{*}{ 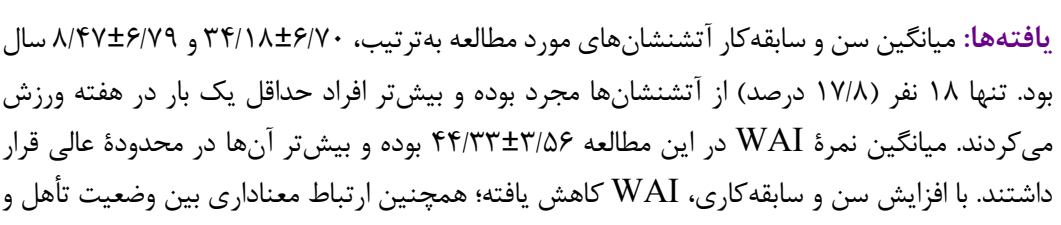 } & دانشكاه علوم يزشكى زاهدان، زاهدان، ايران \\
\hline & 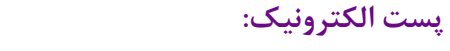 \\
\hline & habybabady568@yahoo.com \\
\hline & براى دانلود اين مقاله، كد زير را با بائ \\
\hline \multirow{3}{*}{ 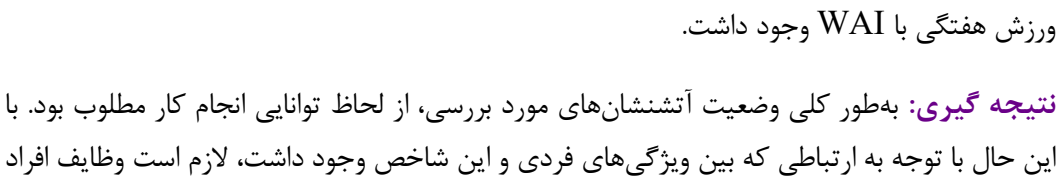 } & STE \\
\hline & \\
\hline & Q6hot \\
\hline & كيىرايت (C) مجله اركونومى؛ دسترسى آزاد؛ كيى \\
\hline ناخص توانايى كار، WAI، آتشنشان & ذبرد منبع آزاد است. \\
\hline
\end{tabular}

نكتهاى كه بايستى به آن توجه كنيم، نقش كليدى انسان

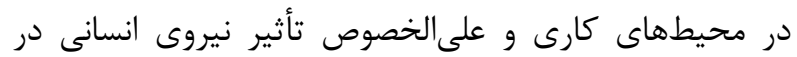

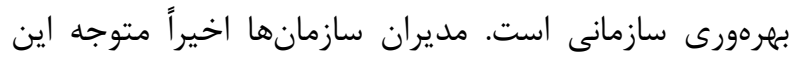

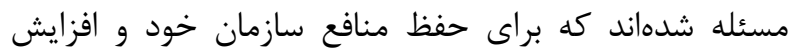
بهرهورى، بايستى به سلامتى نيروى كارى و قابليتهاى او توجه

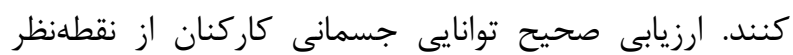
اقتصادى، حايز اهميت است (1) (1). علاوه بر اين، عدم تطابق توانايىهاى فرد با نيازهاى شغلى، مى تواند استرس مضاعفى به

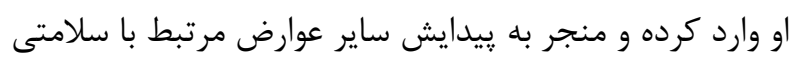

در اغلب مواقع، شرايط محيط كار و ماهيت شغلى افراد،

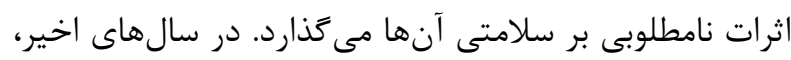

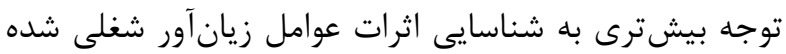

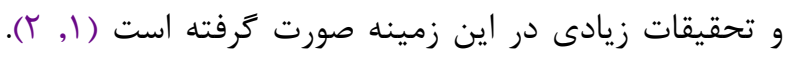

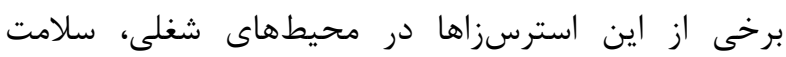

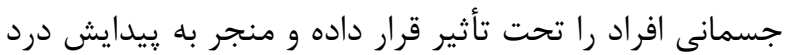
و ناراحتى هايى در سيستم اسكلتى عضلانى افراد شده (Y-Y)

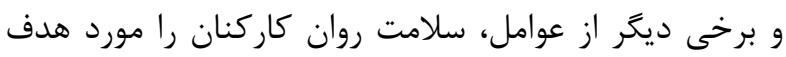

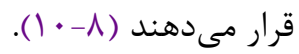


سنگين و ضرورت آمادگى كامل كاركنان در تمام طول شيفت،

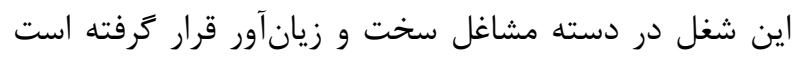

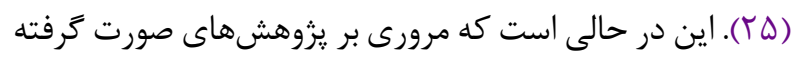
در خصوص شاخص توانايى كار نشان داد كه تاكنون مطالعات بسيار محدودى در داخل كشور منتشر شده كه توانايى انجام كار

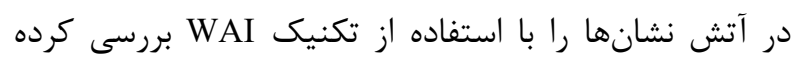

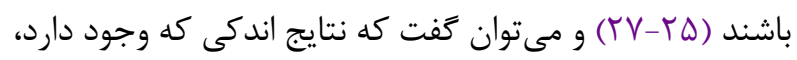

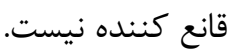
حمل تجهيزات سنخين اطفاى حريق به طبقات ساختمانها،

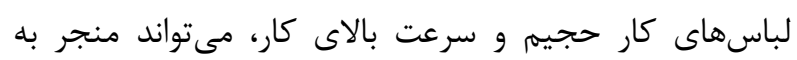

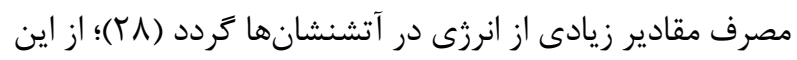

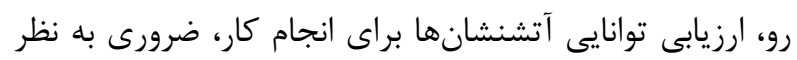

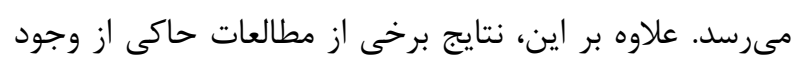

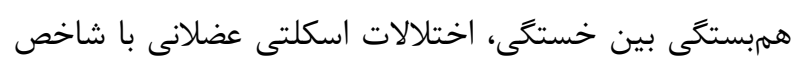

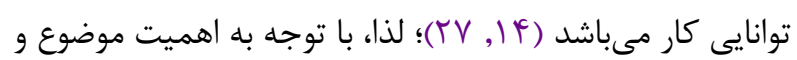

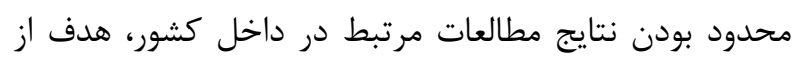

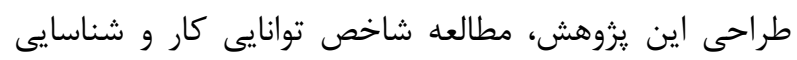

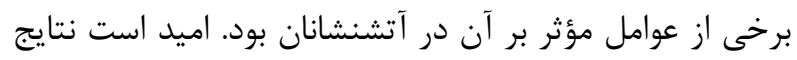
مطالعه حاضر بتواند بستر مناسبى براى تحقيقات آينده فراهم

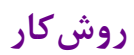

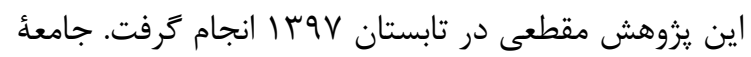

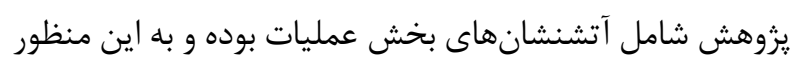

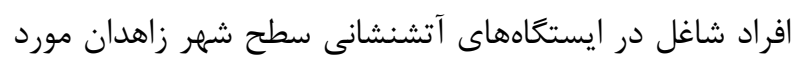

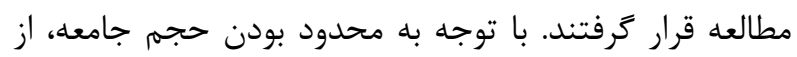

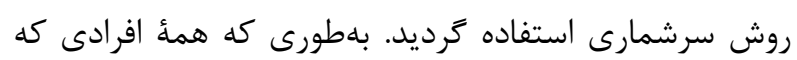
داراى حداقل يك سال سابقهارى بودند وارد مطالعه شدند.

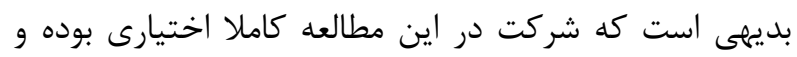

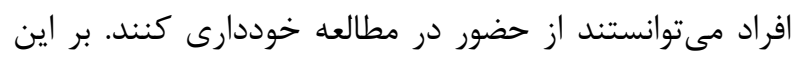
اساس، 1 إ نفر از آتشنشانهاى فعال در ايستخاههاى مذكور

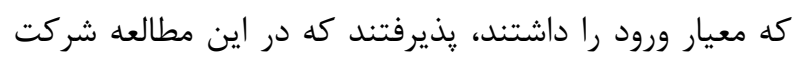

ابزار كردآورى اطلاعات شامل يك يرسش نامه دو قسمتى دئى

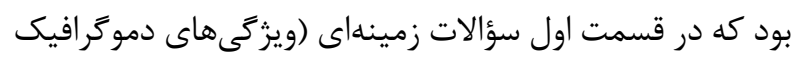

شود. همجنين، همواره بخشى از غيبتهاى ناشى از كار بهدليل

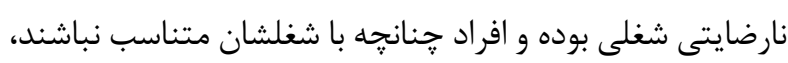

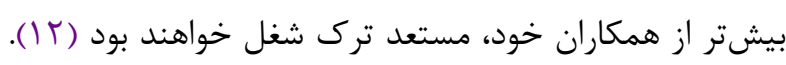

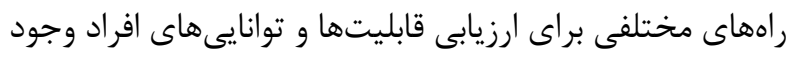

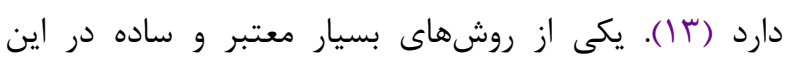

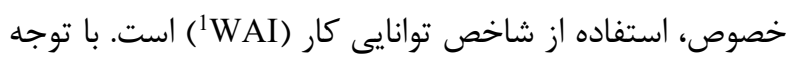
به اين كه WAI يك تكنيك قلم كاغذى است، عدم نياز به

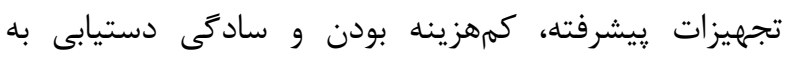

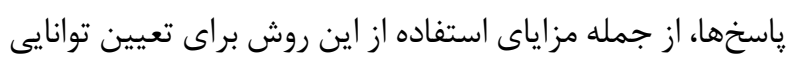

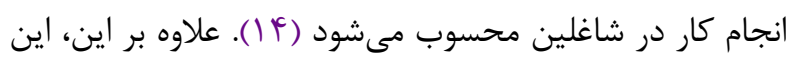

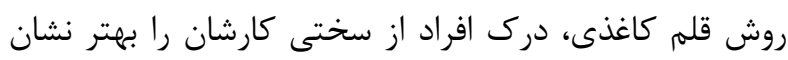

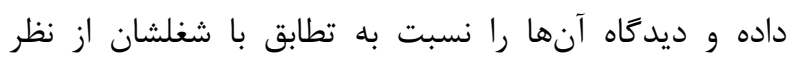

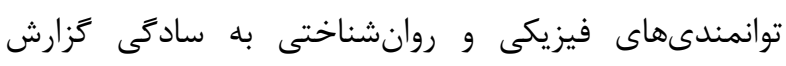

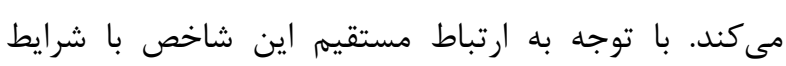

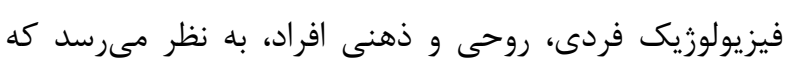

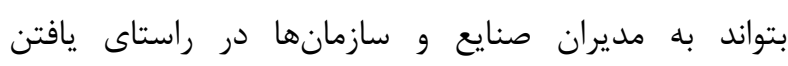

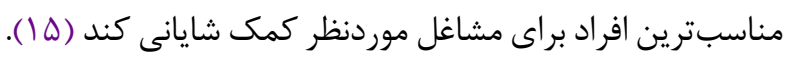
مرور اجمالى مطالعات منتشرشده حوزه شاخص توانايى كار

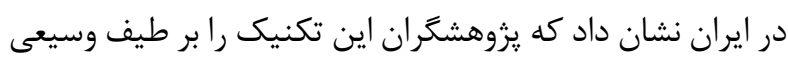

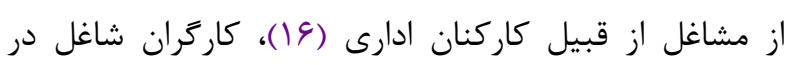

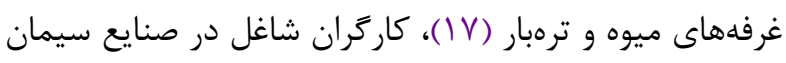

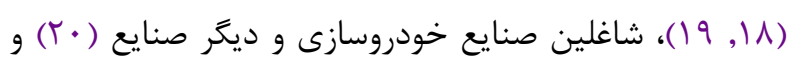

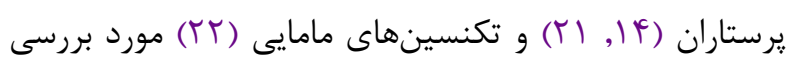

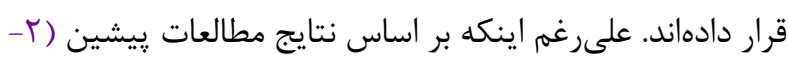

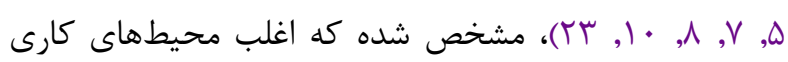

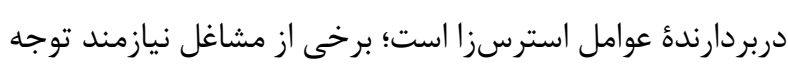

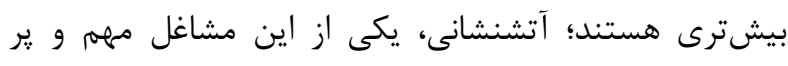

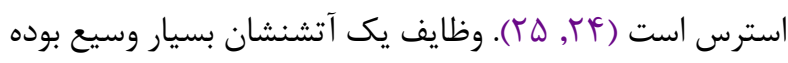

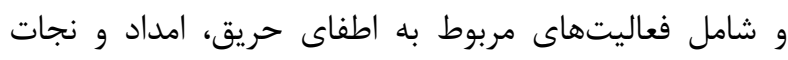

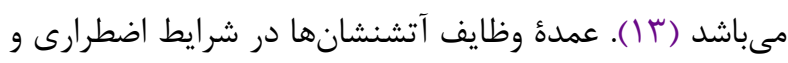
با سرعت و حساسيت بالايى انجام مىشود. اين افراد عموماً

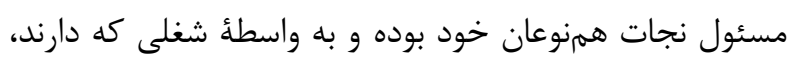
علاوه بر آسيبهاى جسمانى، در معرض آسيبهان همان روانى نيز

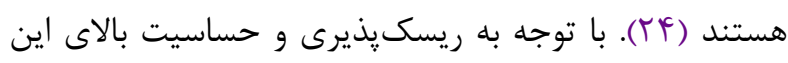

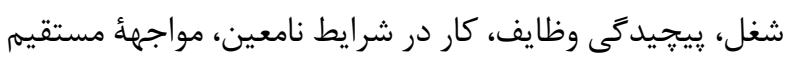

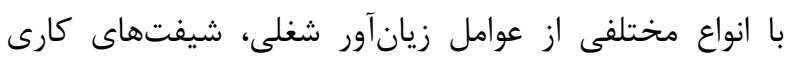


گرفته است (Y9). علاوه بر اين، Mazloumi و همكاران نيز نسخة فارسى آن را بررسى كرده و نتايج مطلوبى را ززارش

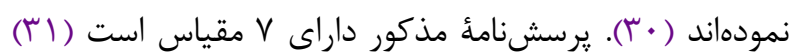

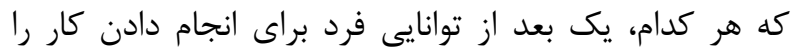

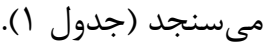

و شغلى) وجود داشته و قسمت دوم دربرگيرنده سؤالات مربوط به بود. WAI بود. يرسشنامة WAI كه براى سنجش توانايى كار افراد در محيطهاى شغلى طراحى شده، برگرفته از انستيتوى تحقيقات بهداشت شغلى فنلاند مىباشد كه توسط Arastoo به زبان فارسى بركردانده شده و روايى و پيايايى آن مورد آزمون قرار

جدول ا. مقياس هاى هفتحًانه شاخص توانايى كار و شيوه نمره كَذارى تز ينه هاى آن

\section{كزينه ها (نمره)}

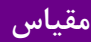

نمره كذارى به صورت خط كشى:

كاملا ناتوان در انجام كار (•)

توانايى كار فعلى در مقايسه با بهترين زمان زندكى

كاملا توانا در انجام كار (· (1)

$$
\begin{aligned}
& \text { خيلى خوب (•) } \\
& \text { نسبتا خوب (^) } \\
& \text { متوسط (9) } \\
& \text { نسبتا ضعيف (F) } \\
& \text { خيلى ضعيف (T) }
\end{aligned}
$$

توانايى كار در ارتباط با نيازهاى جسمانى و روانى شغلى باط باز

ينج بيمارى و يا بيشتر (1)

جهار بيمارى (r)

سه بيمارى (r) (ب)

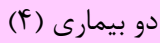

بيمارى هاى فعلى (به تشخيص :زشك)

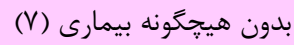

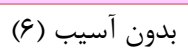

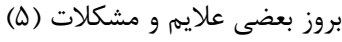

كاهى اوقات ناتوان در انجام كار و مجبور به كاهش سرعت يا تغيير روش انجام

$$
\text { (ז) كار (c) }
$$

اغلب اوقات ناتوان در انجام كار و مجبور به كاهش سرعت يا تغيير روش انجام

توانايى كار كاهش يافته به واسطه بيمارى ها

كار (r)

داشتن توانايى صرفا براى انجام كارهاى ياره وقت (r)

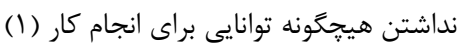

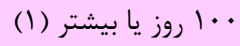
بين बr تا و 9 روز

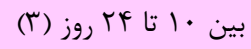

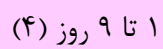
تعداد مرخصى هاى استعلاجى، بيانكر غيبت هاى

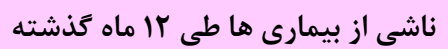

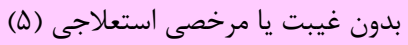

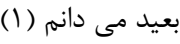

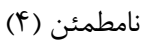

ييشبينى يا بر آورد توانايى كار طى دو سال آينده

تقريبا مطمئن (V) نقمن (F)
هميشه (F)

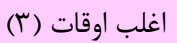
(r) كاهى اوقات أنات (r)
هيج وقت (1)
قابليت هاى فكرى و ذهنى از قبيل لذت بردن از انجام
وظايف روزانه، روحيه فعاليت و زندكى و خوش بـى بينى
نسبت به آينده


جدول r. توصيف متغيرهاى جمعيت شناختى در آتشنشان ها

\section{متغير}

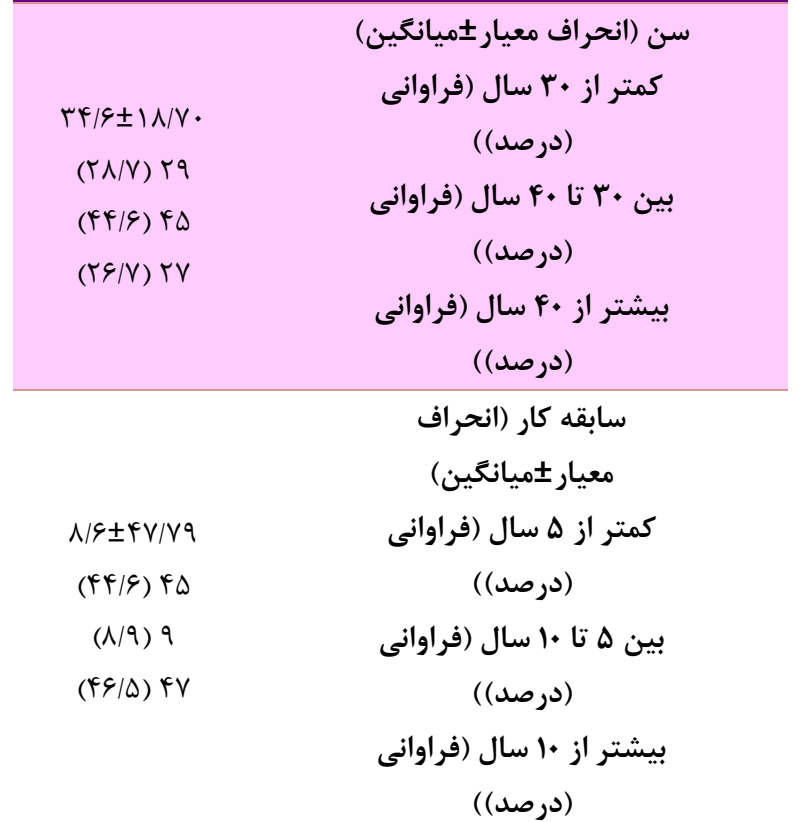

\begin{tabular}{|c|c|}
\hline $\begin{array}{c}r F / r \pm 19 / \varepsilon . \\
(\Delta) \Delta \\
(\Delta r / \Delta) \Delta F \\
(r r / V) r r \\
(\Lambda / q) q\end{array}$ & 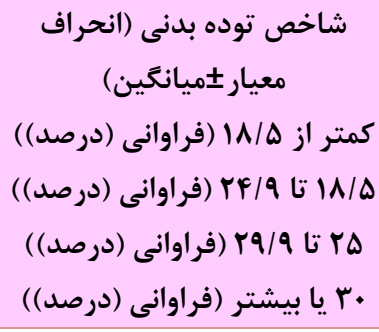 \\
\hline $\begin{array}{l}(I V / \Lambda) \backslash \Lambda \\
(\Lambda T / r) \wedge r\end{array}$ & 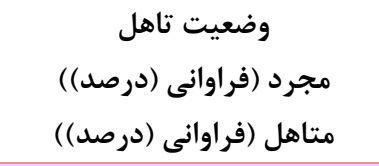 \\
\hline 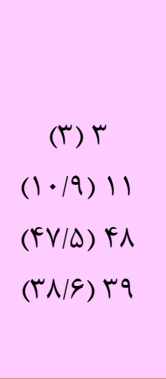 & 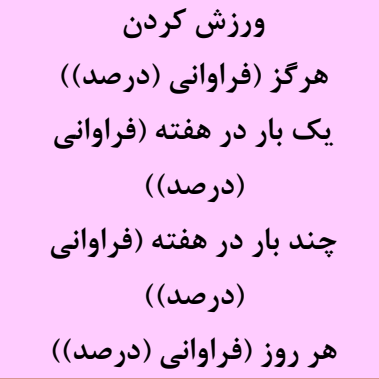 \\
\hline
\end{tabular}

توصيف وضعيت نمرة آتشنشانها در مقياسهاى هفت گانه

و همجنين نمرة كل WAI در جدول r خلاصه شده است.

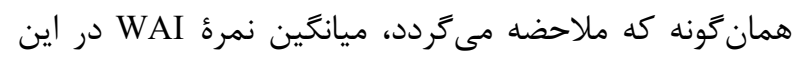

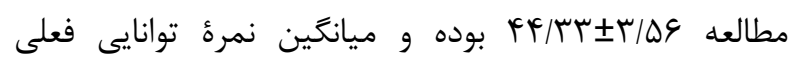

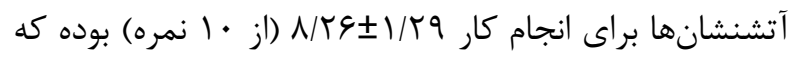

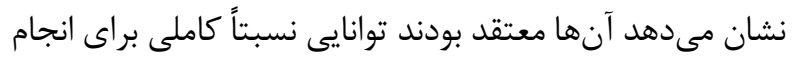
كارشان دارند. همجنين ميانگين نمره كسب شده توسط افراد در مقياس توانايى كار در ارتباط با نيازهاى جسمانى و روانى هميان
بايد توجه داشت كه شاخص توانايى كار، امتيازى است كه از مجموع ابعاد هفت مانه اين يرسشنامه حاصل مىشود. با اين

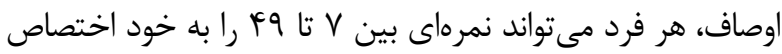
دهد. بديهى است هر جه اين نمره بالاتر باشد، بيانگر توانايى بيشتر

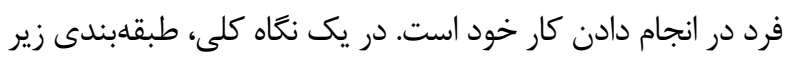
براى شاخص توانايى كار بهصورت كيفى ارائه شده است ( آY): نمرء V تا VV : توانايى انجام كار ضعيف

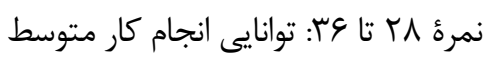

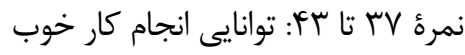

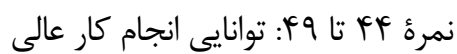
يس از گردآورى اطلاعات، با بهرهگيرى از تكنيكهاى آمار توصيفى و آمار استنباطى (آزمونهاى T مستقل، ANOVA و ضرايب همبستخى ييرسون) در سطح معنادارى ه• • • و و با فاصلة

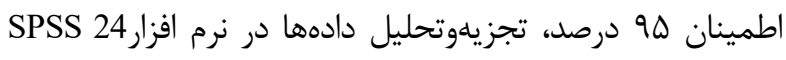
صورت گرفت. (SPSS Inc., Chicago, Ill., USA)

بافته ها

ميانگين سن و سابقهار آتشنشانهاى موردمطالعه در

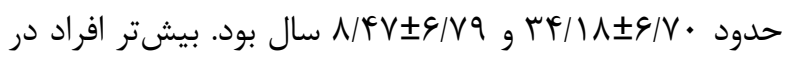

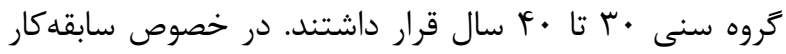
نيز مشخص شد كه بيشتر افراد داراى سابقهكارى كمتر از هـ ه سال و يا سابقهكارى بيشتر از • • سال بودند. علاوه بر اين،

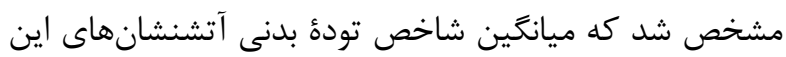

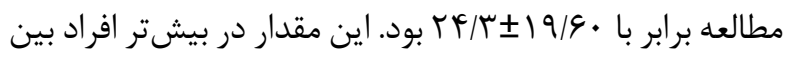

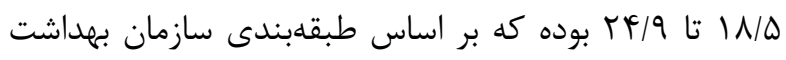
جهانى، محدودهُ طبيعى محسوب مىشود. همجنين نتايج نشان

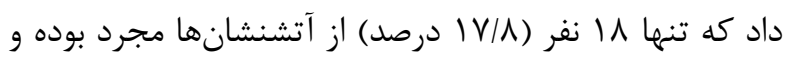
مابقى متأهل بودند. يكى ديخر از متغيرهايى كه بهصورت زمينهاى مورد بررسى قرار كرفت، وضعيت ورزش كردن در بين افراد بود. بر اين اساس مشخص شد كه بيشتر افراد حداقل يك بار در هفته ورزش مى كردند (جدول r). 
بيمارىهاى مورد بررسى، شيوع اغلب بيمارىها ناجيز بوده و

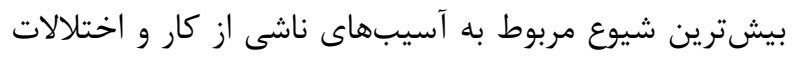
اسكلتى عضلانى (هر دو 1 درصد) بود.

توزيع فراوانى آتشنشانها بر اساس

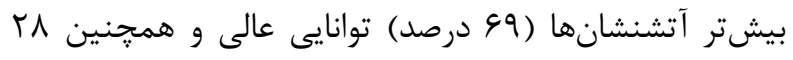

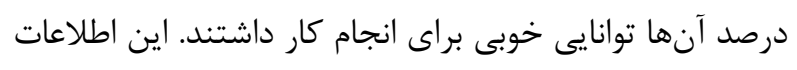
در شكل ا نشان داده شده است.
شغلى نيز بيانكر توانايى نسبتاً خوب آنها مىباشد. توزيع

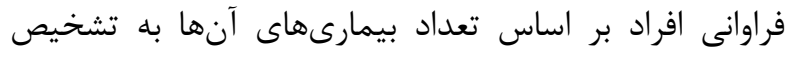

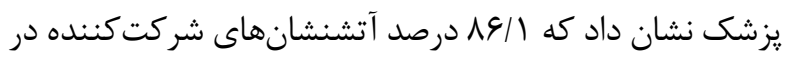

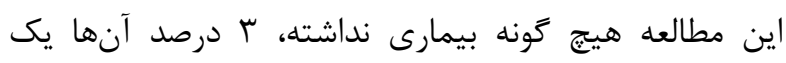

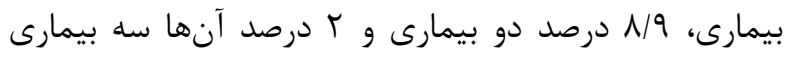

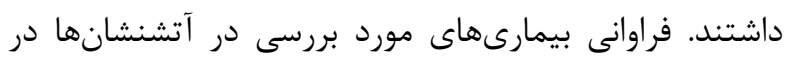

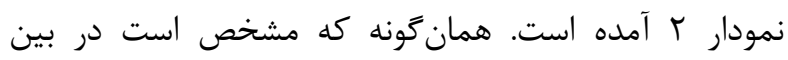

جدول r. توصيف نمره مقياس ها و نمره كل شاخص توانايى كار در آتشنشان ها

\begin{tabular}{|c|c|}
\hline انحراف معيار \يانكين & مقياس \\
\hline$\Lambda / I \pm r \varepsilon / 4 q$ & توانايى كار فعلى در مقايسه با بهترين زمان زندكى \\
\hline$N / I \pm F T / T I$ & توانايى كار در ارتباط با نيازهاى جسمانى و روانى شغلى \\
\hline$\varphi / 1 \pm \Delta 9 / \cdot \uparrow$ & بيمارى هاى فعلى به تشخيص بزشك \\
\hline$\Delta / \cdot \pm \Lambda|/ 9|$ & توانايى كار كاهش يافته به واسطه بيمارى ها \\
\hline$\varphi / \cdot \pm \wedge V / \Delta$ & مرخصى هاى استعلاجى \\
\hline $9 / \cdot \pm 9 V / 94$ & بيشبينى يا بر آورد توانايى كار طى دو سال آينده \\
\hline$r / \cdot \pm V \cdot / \uparrow \wedge$ & قابليت هاى فكرى و ذهنى \\
\hline LY/TITH/DG & شاخص توانايى كار \\
\hline
\end{tabular}

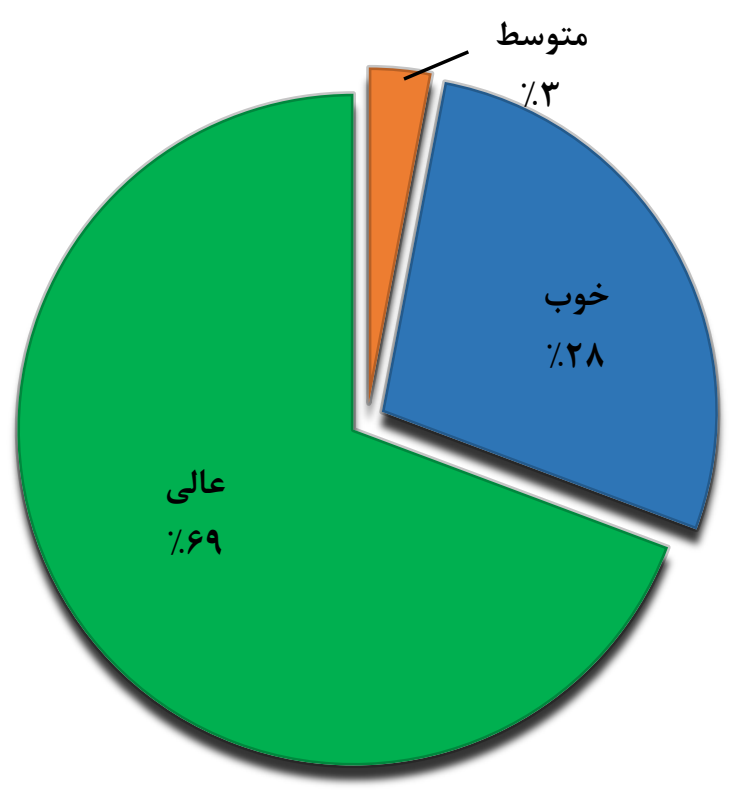

شكل ا. توزيع فراوانى آتشنشانها بر اساس وضعيت شاخص توانايى كار 


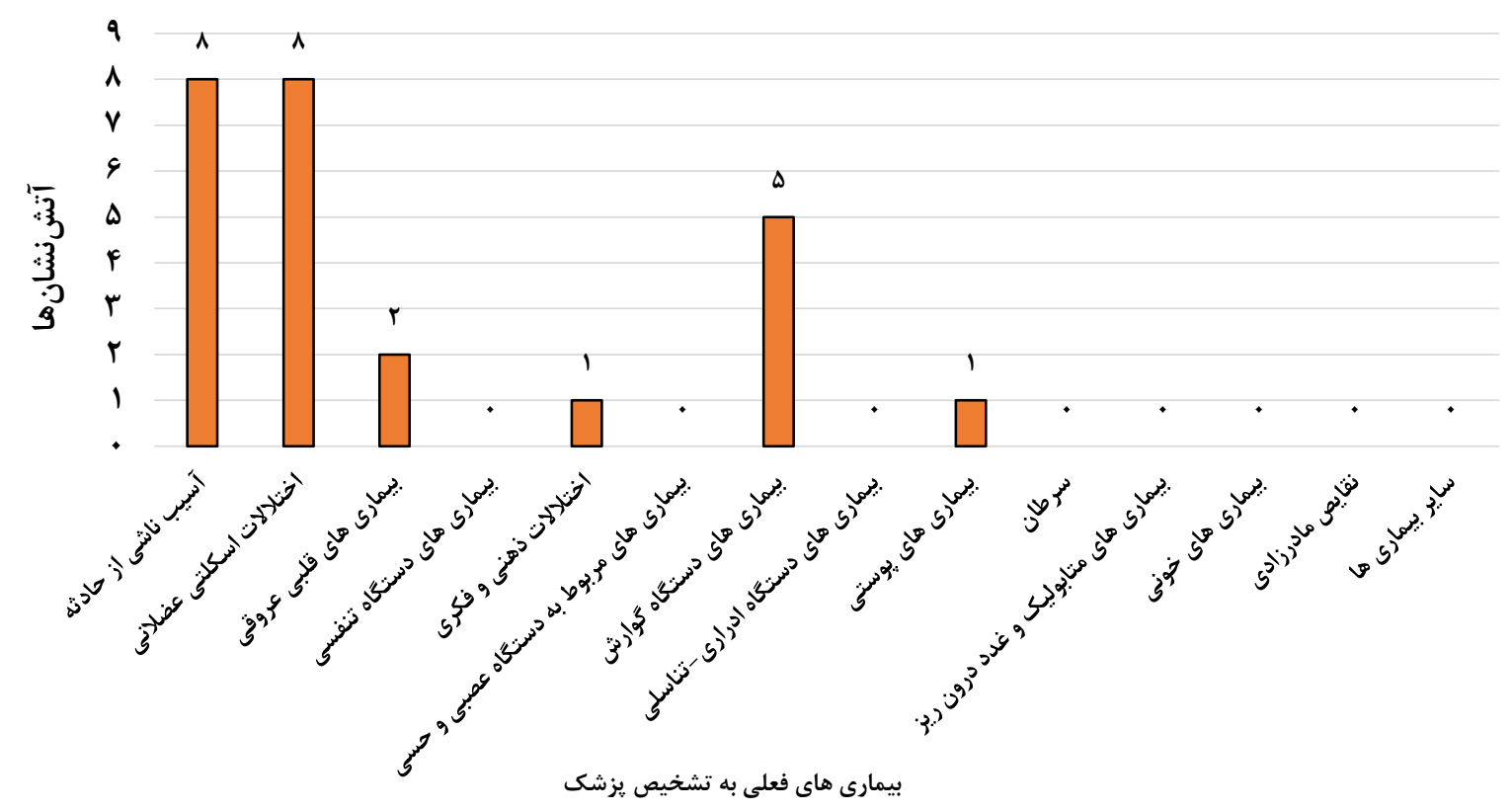

شكل r. توزيع فراوانى بيمارىهاى فعلى بهتشخيص يزشك در آتشنشانها

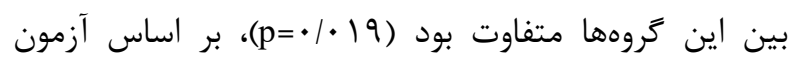

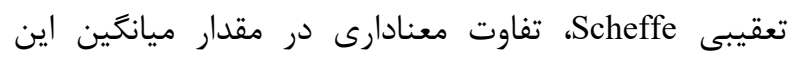

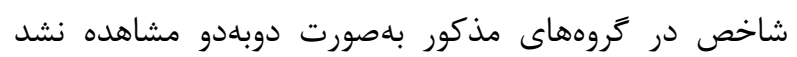
$(P>\cdot / \cdot \Delta)$ همبستگى بين نمرات شاخص توانيى كار با سن، سابقهكار و BMI با كاربرد ضرايب همبستكى ييرسون بررسى شد (جدول

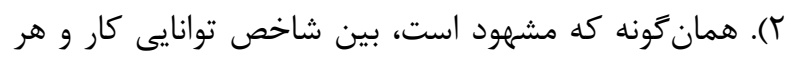

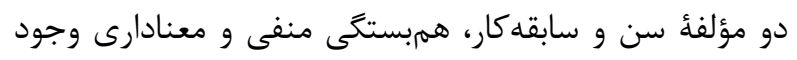

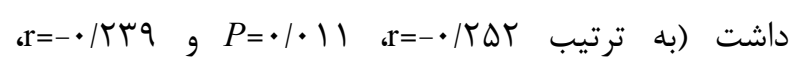

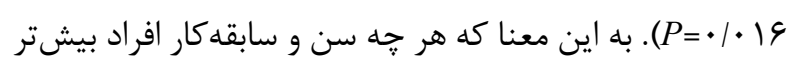

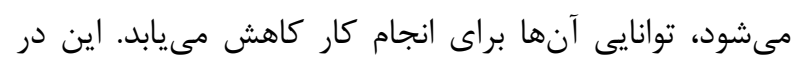

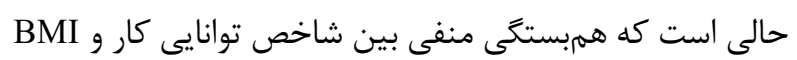

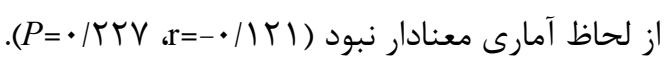

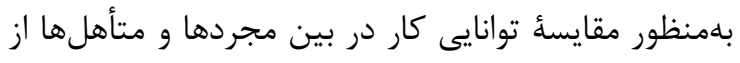

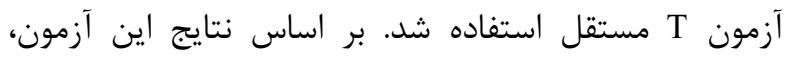

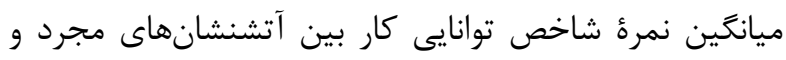

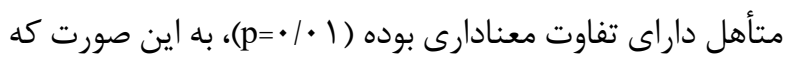

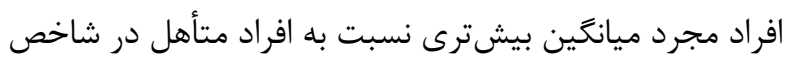

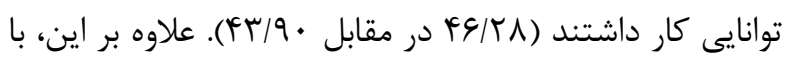

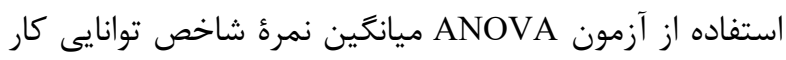

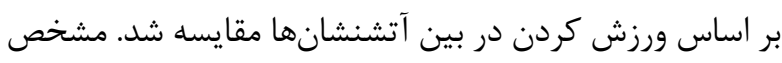

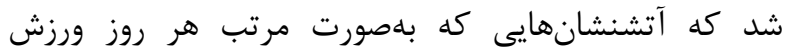

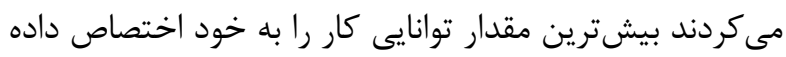

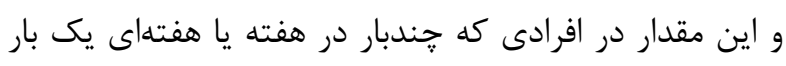

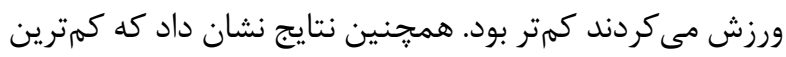

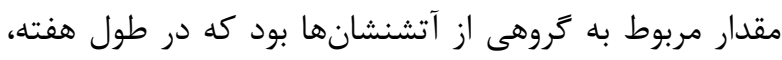

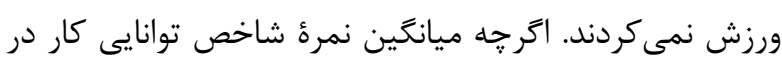

جدول F. همبستكى بين شاخص توانايى كار با سن، سابقهكار و BMI در آتشنشانها

\begin{tabular}{|c|c|c|c|c|}
\hline BMI & سابقه كار & سن & & \\
\hline$-.|| r \mid$ & *_/rrq & $*_{-} \cdot / r \Delta T$ & $\mathbf{r}$ & \multirow{3}{*}{ شاخص توانايى كار } \\
\hline$\cdot / T T V$ & $.1 \cdot 19$ & $.1 \cdot 11$ & P-value & \\
\hline 1.1 & $1 \cdot 1$ & 1.1 & تعداد & \\
\hline \multicolumn{5}{|c|}{ *. همبستكى در سطح ه • • • معنادار مىباشد. } \\
\hline
\end{tabular}

بحث

داد كه ميانكين نمرهٔ شاخص توانايى كار در بين آتشنشانها برابر

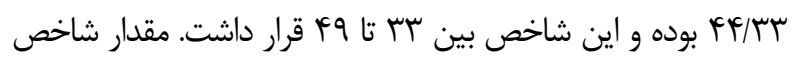

يُوهش حاضر با هدف مطالعهُ شاخص توانايى كار و عوامل مؤثر

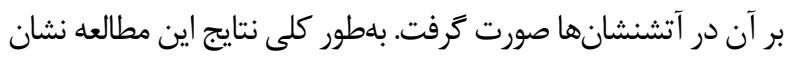


مطالعهُ ما متناقض بود. آنها به اين نتيجه رسيدند كه بين سن و شاخص توانايى كار همبستگى مثبتى وجود دارد (1) (1). مطالعأ

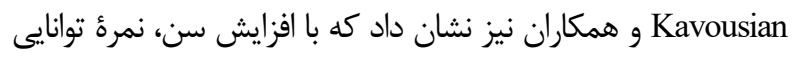
كار افراد كاهش مىيافت كه با نتايج مطالعهُ ما مطابقت دارد (19 (1) ).

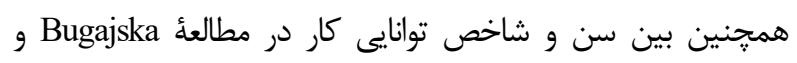

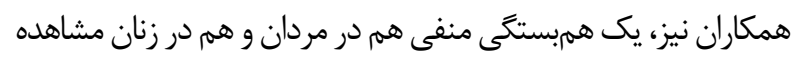

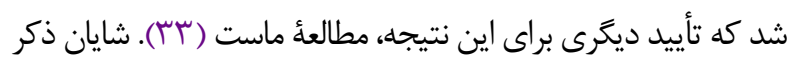

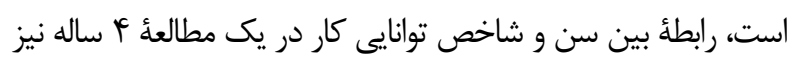
به همين ترتيب كزارش شده كه افزايش سن با كاهش توانايى كار

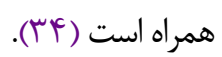
نتايج يزوهش حاضر همجنين نشان داد كه همبستگى منفى و و

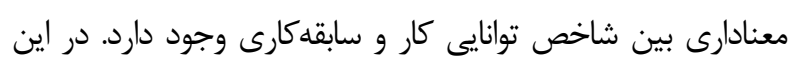

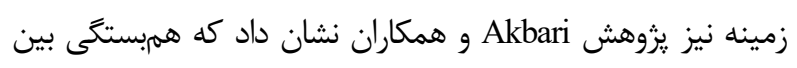

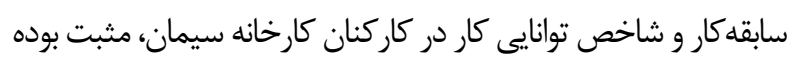

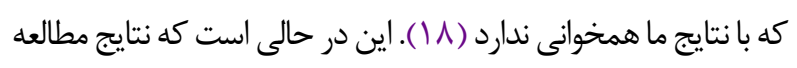
Habibi بالا، شاخص توانايى كار كمترى داشتند كه در راستاى نتايج مطالعهُ ما كان

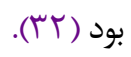
يكى ديكر از يافتههاى اين مطالعه، حول مقايسٔ توانايى كار در

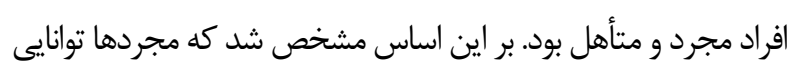

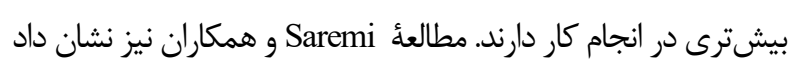

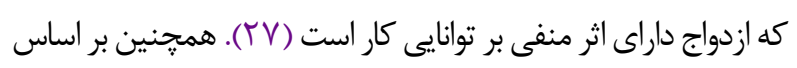

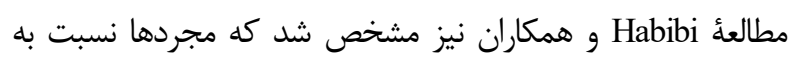

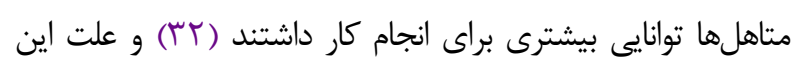

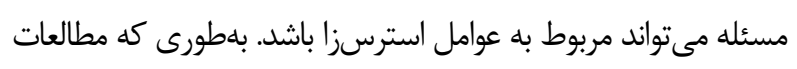

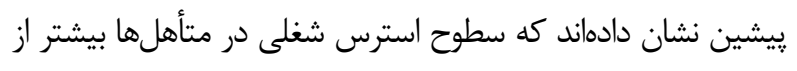
مجردها ست و از طرفى مشخص شده كه بين استرس و توانايى كار،

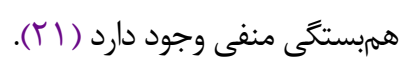
يزوهش حاضر نشان داد كه ورزش منظهم در طول هفته، با افزايش

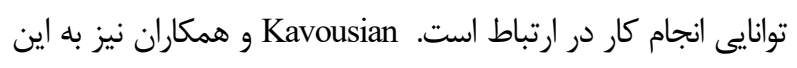

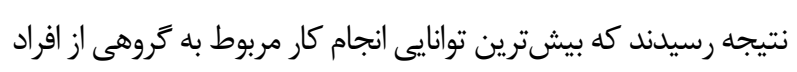

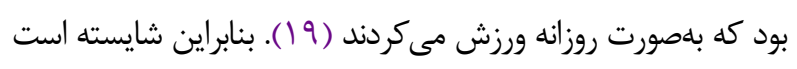
مديران صنايع و سازمانها، جهت دستيابى به سطوح بانه بالاترى از

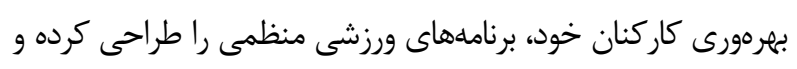

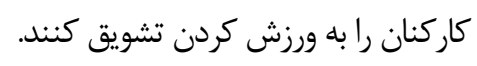

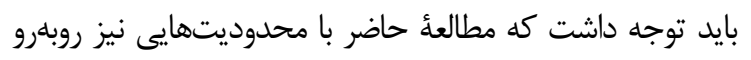
بوده است كه اصلىترين آن، طراحى مقطعى مطالعه بوده و همجهنين

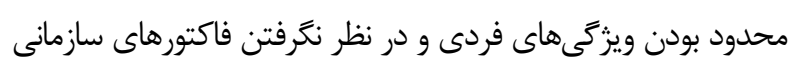

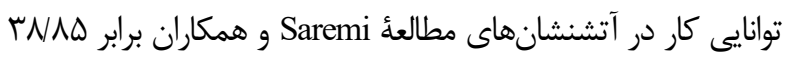

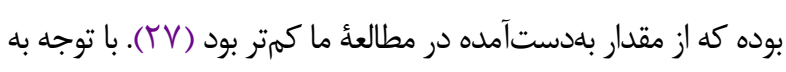

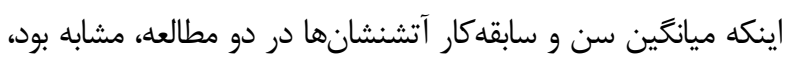

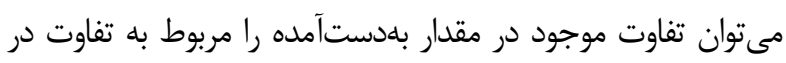

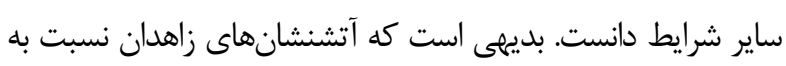

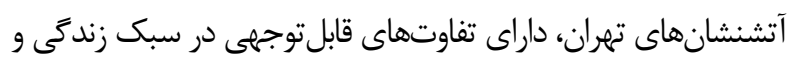

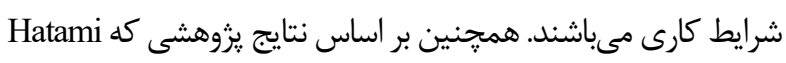

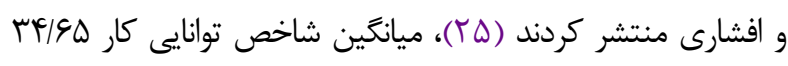

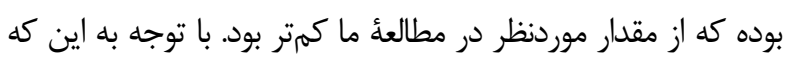

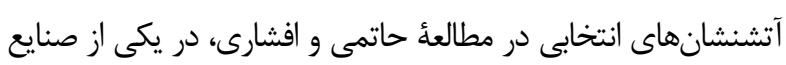

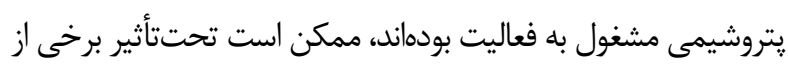

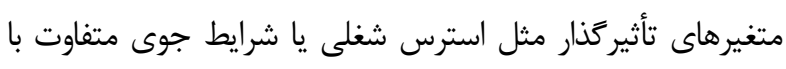

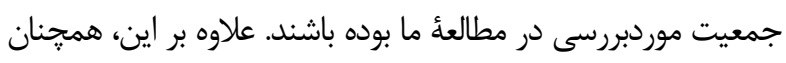

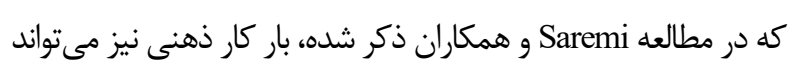

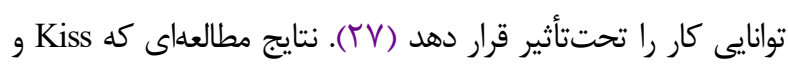

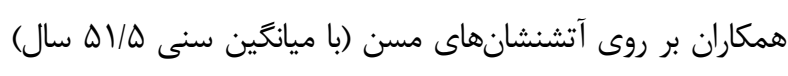

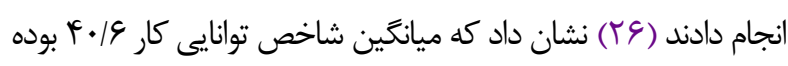

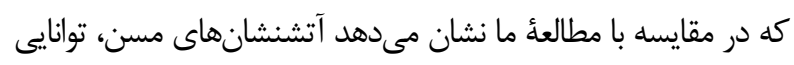
كارى كمترى دارند. بر اساس طبقات شاخص توانايى كار، مشخص شد كه بيشتر

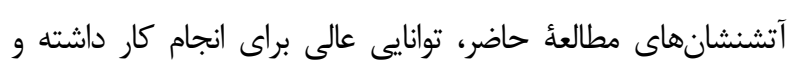

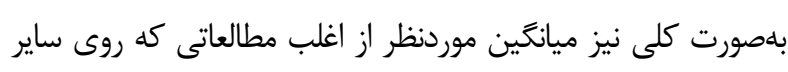

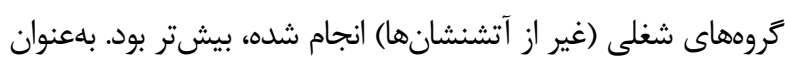

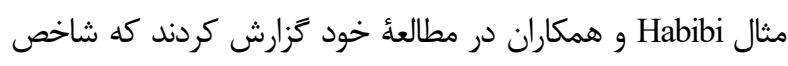

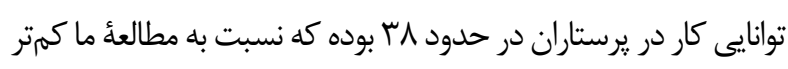

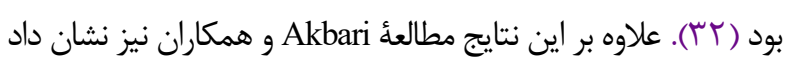

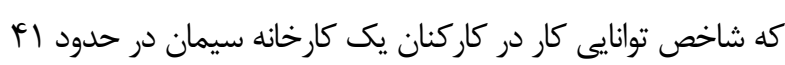

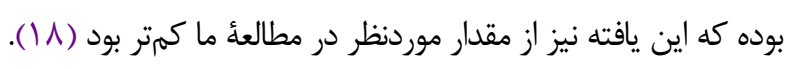

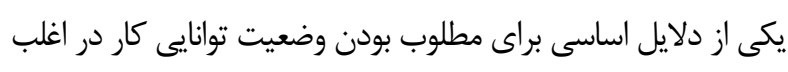

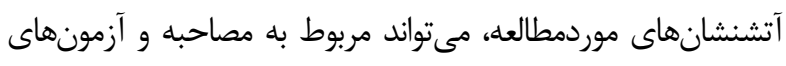

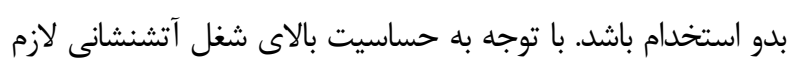

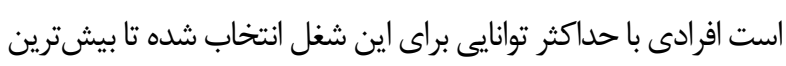

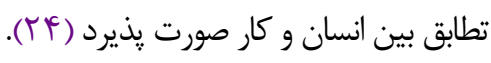

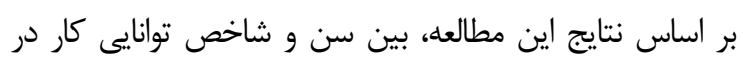

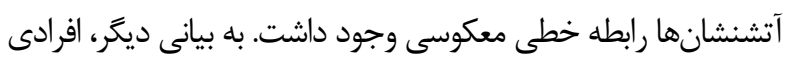

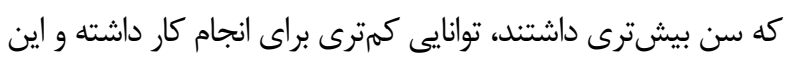

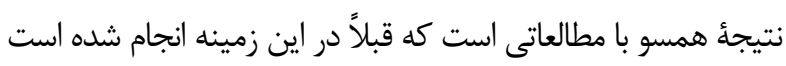

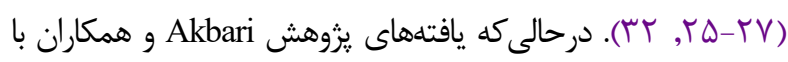


نويسندكان اين مقاله از جنابآقاىمهندس بابك فضلى،

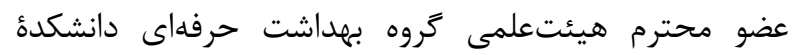
بهداشت زاهدان بابت راهنمايىهاى ارزشمندشان تشكر و و

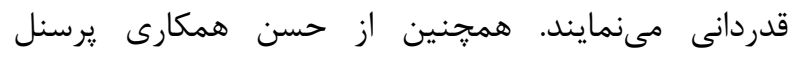

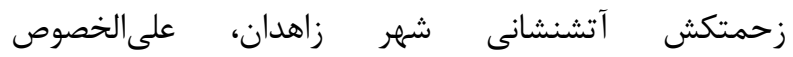

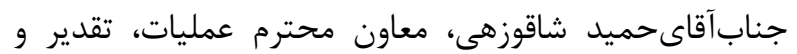
تشكر بهعمل مى آيد. سمهم نويسندگان

راحله هاشمى حبيبآبادى، مطالعه را طراحى و تدوين نموده است. محمدحسين محمودى و سياوش شهنوازى كمك هـ مؤثرى در جمعآورى اطلاعات داشتهاند. رامين رحمانى و هانيه يوسفى تجزيلوتحليل اطلاعات را انجام داده و همجنين ييشنويس اوليئ مقاله را تهيه نمودهاند. در ضمن، همأ نويسندگان نسخئ نهايى مقاله را مطالعه نموده و مسئوليت يزوهش را يذيرفتهاند. تعارض منافع

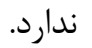
منابع مالى ندارد.

\section{References}

1. Laposa JM, Alden LE, Fullerton LM. Work stress and posttraumatic stress disorder in ED nurses/personnel (CE). J Emerg Nurs. 2003;29(1):23-8. [DOI:10.1067/men.2003.7] [PMID]

2. Thomas RJ. Occupational Health-Recognizing and Preventing Work-Related Disease and Injury. J Occup Environ Med. 2000;42(11):1131-2. [DOI:10.1097/00043764-200011000-00021]

3. Ghasemi F, Gholamizadeh K, Doosti-Irani A, Rahmani R. Comparison of Strain Index (SI) and ACGIH-HAL in Assessing the Risk of Upper Extremities Disorders and Prediction of Carpal Tunnel Syndrome in Butchers. J Ergon. 2019;6(4):1-8. [DOI:10.30699/jergon.6.4.1]

4. Rahmani R, Shahnavazi S, Fazli B, Ghasemi F. Ergonomic assessment of musculoskeletal disorders risk in a cement factory workers using QEC technique. Pajouhan Sci J. 2020;18(2):83-90.

5. Ghasemi F, Gholamizadeh K, Rahmani R, Doosti-Irani A. Prevalence and severity of carpal tunnel syndrome symptoms among Iranian butchers and their association with occupational risk factors: Implications for
ديخر از قبيل رضايت شغلى يا استرس شغلى و همجنين عدمتوجه به برخى از فاكتورهاى فردى از قبيل مصرف سيكار از جمله

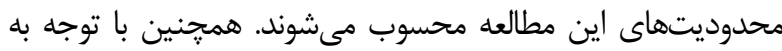
اينكه جمعيت موردمطالعه همگَى مرد بودند، قادر به بررسى تأثير جنسيت بر توانايى انجام كار نبوديم. بنابراين نويسندكان توصيه مى كنند كه مطالعات جامعترى طراحى و اجرا گردد تا ساير عوامل مؤثر بر توانايى انجام كار شناسايى شده و كامهاى مؤثرى در جهت ارتقاى شرايط محيط كار در راستاى بهبود توانايى افراد و افزايش بهرهورى برداشته شود.

$$
\text { نتيجه كَيرى }
$$

بر اساس نتايج اين يزوهش مشخص شد كه بهطور كلى وضعيت آتشنشانهاى موردبررسى از لحاظ توانايى انجام كار

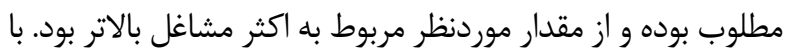

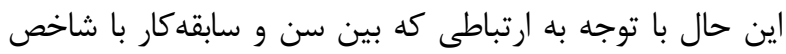

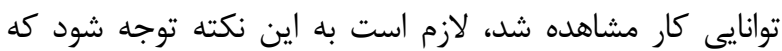
كاهش توانايى در افراد مسن و با سابقهكارى بالا، مىطلبد كه از اين افراد در وظايف نسبتاً سادهتر اين شغل استفاده شده و همجنين با توجه به تأثير مثبتى كه ورزش كردن بر ارتقاى سطح توانايى افراد براى انجام كار دارد، لازم است تدابيرى در جهت تشئ تشويق بيشتر كاركنان به ورزش منظم در طول هفته انديشيده شود. تقدير و تشكر

ergonomic interventions. Work. 2020;66(4):817-25. [DOI:10.3233/WOR-203227] [PMID]

6. Smith DR, Mihashi M, Adachi Y, Koga H, Ishitake T. A detailed analysis of musculoskeletal disorder risk factors among Japanese nurses. J Safe Res. 2006;37(2):195-200. [DOI:10.1016/i.jsr.2006.01.004] [PMID]

7. Da Costa BR, Vieira ER. Risk factors for work-related musculoskeletal disorders: a systematic review of recent longitudinal studies. Am J Ind Med. 2010;53(3):285-323. [DOI:10.1002/ajim.20750] [PMID]

8. Almasi Z, Hashemi Habybabady R, Rahmani R. The study of Mental Health Status and Its Effective Factors among Zahedan City's Welders. Pajouhan Sci J. 2020;18(2):30-8

9. Harvey SB, Modini M, Joyce S, Milligan-Saville JS, Tan L, Mykletun A, et al. Can work make you mentally ill? A systematic meta-review of work-related risk factors for common mental health problems. Occu Environ Med. 2017;74(4):301-10. [DOI:10.1136/oemed-2016-104015] [PMID] 
10. Henderson M, Harvey SB, Øverland S, Mykletun A, Hotopf M. Work and common psychiatric disorders. J R Soc Med. 2011;104(5):198-207. [DOI:10.1258/jrsm.2011.100231] [PMID] [PMCID]

11. Costa G, Sartori S. Ageing, working hours and work ability. Ergo. 2007;50(11):1914-30. [DOI:10.1080/00140130701676054] [PMID]

12. Rahmani R, Ebrazeh A, Zandi F, Rouhi R, Zandi S. Comparison of job satisfaction and job stress among nurses, operating room and anesthesia staff. J Ergon. 2020;8(4):0-.

13. Lindberg A-S, Oksa J, Malm C. Laboratory or field tests for evaluating firefighters' work capacity? PloS one. 2014;9(3):e91215. [PMID] [PMCID] [DOI:10.1371/journal.pone.0091215]

14. Ehsan G, Sharif N, Adel M, Mojtaba D, Masoumeh A. Relationship between Work Ability Index and Fatigue among Iranian Critical Care Nurses. Int J Occup Hyg. 2018;10(3):135-42.

15. Alexopoulos EC, Merekoulias G, Gnardellis C, Jelastopulu E. Work ability index: validation of the Greek version and descriptive data in heavy industry employees. J Adv Med Med Res. 2013;3(3):608-21. [DOI:10.9734/BJMMR/2013/2552]

16. Ordudari Z, Soury S, Habibi E, Sharifian Z. The Relationship Between the Physical Activity and Work Ability Index in Office and Operations Jobs. J Ergon. 2018;6(2):1-9. [DOI:10.30699/jergon.6.2.55]

17. Poyakian M, Zakerian SA, Avakh A, Khodakarim S, Mohammadian F, Kangavari M. Worker's Work Ability Index In The Fruit And Vegetable Stands In Tehran In 2014. Pajouhan Sci J. 2015;13(4):34-41.

18. Akbari F, Fazli B, Jafari H, Almasi Z. The Relationship Between Work Ability Index and Individual Characteristics of Zabol Cement Company Employees in 2017: A Short Report. J Rafsanjan Univ Med Sci. 2018;17(5):485-92.

19. Kavousian M, Jafari M, Khodakarim S, Rabiei H. Investigation of work ability index (WAI) and its relationship with maximal aerobic capacity (VO2max) among cement industry employer. Occup Med. 2020;12(2):36-46. [DOI:10.18502/tkj.v12i2.4372]

20. Kalte HO, Hamamizadeh E, Faghih MA, Faghih A. The effect of body mass index and exercise activity on the work ability index among staff of Pegah Company. J Prev Med. 2016;3(2):1-10.

21. Samadi S, Golmohammadi A. Study the relation between occupational stress and work ability index among nurses of selected military hospital. J Police Med. 2013;2(4):223-30.

22. Safaei M, Abedian Z, Mazlum SR. Relationship between job stress and work ability among Mashhad health centers employed midwives. J Torbat Heydariyeh Univ Med Sci (Journal of Health Chimes). 2016;4(1):30-5.
23. Ghasemi F, Rahmani R, Behmaneshpour F, Fazli B. Quality of work life among surgeons and its association with musculoskeletal complaints. Cogent Psychol. 2021;8(1):1880256. [DOI:10.1080/23311908.2021.1880256]

24. Hashemi Habybabady R, Ghaderi N, Rahmani R, Mohammadi M. Estimation of Maximum Aerobic Capacity and its Related Factors Using Treadmill Test in Firefighters of Zahedan. J North Khorasan Univ Med Sci. 2018;10(1):1-8.

25. Hatami A, Afshari D. Effect of Occupational Stress on the Work Ability of Iranian Firefighters. Jundishapur J Health Sci. 2019;11(1). [DOI:10.5812/jihs.83410]

26. Kiss $\mathrm{P}$, Walgraeve M, Vanhoorne M. Assessment of work ability in aging fire fighters by means of the Work Ability Index Preliminary results. Arch public health. 2002;60(34):233-43.

27. Saremi M, Madvari RF, Laal F, Noorizadeh N, Rahimi E. Assessment of mental workload, workability and musculoskeletal disorders of firefighters. J Community Health Res. 2019;8(3):139-47. [DOI:10.18502/jchr.v8i3.1562]

28. Pollock RD, Provan S, Martin FC, Newham DJ. The effects of whole body vibration on balance, joint position sense and cutaneous sensation. Eur J Appl Physiol. 2011;111(12):3069-77. [DOI:10.1007/s00421-011-1943y] [PMID]

29. Arastoo AA, Montazeri A, Abdolalizadeh M, Ghasemzadeh R, Ahmadi K, Azizi A. Psychometric properties of Persian version of the Work Ability Index questionnaire. Payesh (Health Monit). 2013;12(5):53543.

30. Mazloumi A, Kazemi Z, Eivazlou M. Validation and reliability study of farsi version of work ability index questionnaire. J Sch Public Health Inst Public Health Res. 2014;12(1):61-74.

31. Alavi nia SM, Hoseeini SH. Work ability index, an important tool in occupational health and medicine to define workers at risk for early exit from work force. J North Khorasan Univ Med Sci. 2011;3(2):53-49. [DOI:10.29252/jnkums.3.2.49]

32. Habibi E, Dehghan H, Zeinodini M, Yousefi HA, Hasanzadeh A. The Relation between Work Ability Index and Physical Work Capacity based on Fox Equation for VO2 Max in Male Nursing Staff of Isfahan Hospitals, Iran. Health Syst Res. 2011;7(5):606-14.

33. Bugajska J, Makowiec-Dąbrowska T, Jegier A, Marszałek A. Physical work capacity (VO2 max) and work ability (WAI) of active employees (men and women) in Poland. Elsevier. 2005 0531-5131. [DOI:10.1016/j.ics.2005.03.001]

34. Tuomi K, Luostarinen T, Ilmarinen J, Klockars M. Work load and individual factors affecting work disability among aging municipal employees. Scand J work Environ health. 1991;17:94-8. 